of light, which is based on a large number of observations.

Measurements of the velocity in a vacuum have been made, using the $E_{010}$ and $E_{011}$ modes in one particular resonator. The values of the velocity term obtained for the two modes differ by 2 parts in $10^{5}$, the average value for the velocity of electric waves in a vacuum being

$$
v_{0}=299,793 \mathrm{~km} \cdot / \mathrm{s} \text {. }
$$

The maximum error, including residual effects due to the method of coupling the resonator to a source of oscillations, is estimated to be \pm 3 parts in $10^{5}$, which is approximately $\pm 9 \mathrm{~km} . / \mathrm{s}$.

The value of velocity is $17 \mathrm{~km}$./s. greater than that generally accepted for the velocity of light, although the values are not in disagreement when the combined limits of error are taken into account. In view of the possible discrepancy, however, it is proposed to make measurements of other modes in resonators of different shapes, in order to obtain further experimental evidence of the possible sources of error.

National Physical Laboratory,

L. Essen

Teddington.

Feb. 19 .

\section{Resolution of Mepacrine}

MEPACRINE (2-chloro-5-( $\delta$-diethylamino- $\alpha$-methylbutyl)amino-7-methoxyacridine) has been resolved by Tschelincev and Osetrova ${ }^{1}$, by the use of what they describe as $\alpha \alpha^{\prime}$-bromeamphorsulphonic acid.

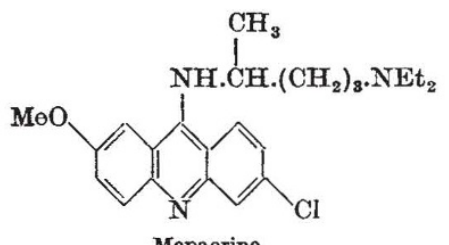

We have failed to effect resolution with any of the available bromeamphorsulphonic acids, though Dr. Trenner, of Merck and Co., U.S.A., has succeeded with $d$ - $\alpha$-bromcamphor- $\pi$-sulphonic acid ${ }^{2}$. We have, however, carried out a complete resolution by means of $d-4: 6: 4^{\prime}: 6^{\prime}$-tetranitrodiphenic acid. Full details will be given in another place; in the meantime, we wish to record our values for the specific rotation of the hydrochlorides of the optical antimers in water. We find :

$[\alpha]_{D}^{14^{\circ}}=-379 \pm 6^{\circ}$ (m.p. 244-5 $5^{\circ}$, decomp.; uneorr.).

$[\alpha]_{D}^{10^{\circ}}=+388 \pm 7^{\circ}$ (m.p. 244-5 $5^{\circ}$, decomp.; uncorr.).

Tschelincev and Osetrova ${ }^{1}$ give :

$[\alpha]_{D}=-357^{\circ}$ (m.p. $243^{\circ}$, decomp.).

$[\alpha]_{D}=+358 \cdot 6^{\circ}$ (m.p. $243^{\circ}$, decomp.).

B. R. Brown

D. Lr. HAMmick

Dyson Perrins Laboratory,

Oxford.

Feb. 27.

${ }^{1}$ Tschelincev and Osetrova, J. Gen. Chem. (Rus8.), 10, 1978 (1940). 2 Bacher, Buhs, Hetrick, Reiss and Trenner, J. Amer. Chem. Soc., April 1947 .

\section{Polymerization of a Semiquinone lon}

THE most recent theory of the structure of Wurster type dyes (oxidation products of $p$-phenylenediamines) is that of Granick and Michaelis ${ }^{1}$. One of their main conclusions was that polymerization of a semiquinone ion of the type depicted below is impossible<smiles></smiles>

when all the amino hydrogens are substituted. In support of this conclusion, they instanced the existence of a crystalline perchlorate of Wurster's Blue (the oxidation product or $\delta$-salt of tetramethyl paraphenylenediamine $)^{2}$ the paramagnetism of which indicates the presence in the molecule of one unpaired electron.

By oxidizing tetramethylbenzidine with aqueous bromine in the presence of sodium perchlorate, we have prepared a deep-green crystalline perchlorate which catalytic micro-reduction shows to be on the oxidation level of a semiquinone. The striking thing about this green salt is that it is diamagnetic $\left(\psi_{M}=-166 \times 10^{-6}\right.$ c.g.s. units). Thus polymerization of this semiquinone ion occurs in spite of the fact that all the amino hydrogens are substituted. It is clear that some modification of the existing theory of polymerization of semiquinone ions of the above type is required. Details of proposed modifications and work on related compounds will be published shortly.

G. K. Hughes

N. Hush

D. P. MFLLOR

Department of Organic and Applied Chemistry, Department of Chemistry, University of Sydney. Feb. 27.

${ }^{1}$ Michaelis, L., and Granick, S., J. Amer. Chem. Soc., 65, 1747 (1943). 2 The paramagnetism of the perchlorate of Wurster's Blue was first studied by H. Katz, Z. Phys., 87, 242 (1933).

\section{Size Versus Colour in Air-Sea Rescue}

I AM indebted to the Air Ministry and especially to the civilian staff of the Air-Sea Warfare Development Unit for a copy of the valuable report on "The Optimum Dinghy Colour for Air-Sea Rescue". Colours were tried from a yellow close to the Schott glass O.G.1, through orange and fire orange, near Schott O.G.2, onwards to traffic red and post-office red, like Schott R.G.l. The overall average visual range of the five coloured $M$-type dinghies for all-round weather conditions around the British Isles was approximately 1.7 nautical miles $(3.15 \mathrm{~km}$.). The waters were mostly greenish, but this is not always so on our coasts.

For the blue Mediterranean the visual ranges were, yellow dinghy 4 naut. miles $(7 \cdot 41 \mathrm{~km}$.) ; orange and fire orange, 3 naut. miles $(5.56 \mathrm{~km}$.) ; reds, 2.5 naut. miles $(4 \cdot 63 \mathrm{~km}$.). These are significantly different. But there was no such difference between the maximum visibility distance as a definitely coloured object on any sea colour. On green and blue seas, the ob. servers favoured dinghies which appeared orange. This agrees with my own observations using the Schott glasses at sea, for the clearest view is obtain. able with O.G.2. 